\title{
Percepciones de los docentes sobre un proceso formativo con la educación CTS en educación básica
}

\author{
Vanessa Candito ${ }^{(*)}$ \\ vanecandito@gmail.com \\ http://orcid.org/0000-0003-4663-9590
}

Karla Mendonça Menezes (*)

karlam.ef@gmail.com

http://orcid.org/0000-0002-7482-0648

Carolina Braz Carlan Rodrigues (*)

carolinabcarlan@gmail.com

http://orcid.org/0000-0001-7115-0987

Maria Rosa Chitolina Schetinger ${ }^{(*)}$

mariachitolina@gmail.com

https://orcid.org/0000-0002-5240-8935

${ }^{(*)}$ Universidade Federal de Santa Maria (UFSM)

Santa Maria, Brasil.

Recibido: 29/março/2021 Aceptado: 30/agosto/2021

\section{Resumen}

A educación continua contribuye a la constante evolución de la labor docente y permite la construcción de conocimientos para transformar las prácticas educativas, ayudando también a superar las dificultades encontradas en el aula. El objetivo de este estudio fue analizar las percepciones de los docentes sobre un proceso formativo, desde el enfoque CTS, para la práctica docente. El proceso formativo se llevó a cabo con profesores de primaria y secundaria, en una escuela pública, en Santa María, Rio Grande do Sul (RS), mediado por talleres pedagógicos, que incluyeron el enfoque CTS en el contexto escolar. Los datos se obtuvieron a través de un cuestionario semiestructurado, compuesto por dos preguntas, y posteriormente se utilizó la metodología de análisis de contenido para analizar los datos. Los resultados evidenciaron aportes en las prácticas docentes, asociados principalmente a las nuevas estrategias de enseñanza, que colaboraron para el desarrollo de los educadores y favorecieron una enseñanza interdisciplinar y contextualizada. La educación continua también indicó beneficios como la motivación e interacción de los estudiantes, favoreciendo así la enseñanza y el aprendizaje. Por tanto, es parte indispensable en la formación de docentes, propuestas como el enfoque CTS en el contexto escolar, ya que colaboró para repensar la formación, y benefició acciones centradas en reflexiones sobre la práctica pedagógica.

Palabras clave: Ciencia-Tecnología-Sociedad. Práctica docente. Formación continua del profesorado. 


\title{
Percepções docentes sobre um processo formativo com educação CTS na educação básica
}

\begin{abstract}
Resumo
A formação continuada contribui para a evolução constante do trabalho docente e permite a construção de conhecimentos para transformar as práticas educativas, auxiliando também na superação das dificuldades encontradas em sala de aula. O objetivo desse estudo foi analisar as percepções dos professores sobre um processo formativo, a partir do enfoque CTS, para a prática docente. O processo formativo foi realizado com docentes do Ensino Fundamental e Médio, em uma escola da rede pública de Santa Maria, Rio Grande do Sul (RS), mediado por oficinas pedagógicas, que contemplou o enfoque CTS no contexto escolar. Os dados foram obtidos por meio de um questionário semiestruturado, composto por duas questões, e posteriormente utilizou-se a metodologia de análise de conteúdo para apreciar os dados. Os resultados demonstraram contribuições nas práticas docentes, associadas sobretudo a novas estratégias de ensino, que colaboraram para o desenvolvimento dos educadores, e favoreceram um ensino interdisciplinar e contextualizado. A formação continuada também indicou benefícios como a motivação e interação dos estudantes, assim favorecendo o ensino-aprendizagem. Sendo assim, faz-se como parte indispensável na formação de professores, propostas como o enfoque CTS no contexto escolar, visto que cooperou para o repensar sobre a formação, e beneficiou ações centradas em reflexões sobre a prática pedagógica.
\end{abstract}

Palavras chave: Ciência-Tecnologia-Sociedade. Prática docente. Formação continuada de professores.

\section{Teachers' perceptions about a formative process with STS education in basic education}

\begin{abstract}
Continuing education contributes to the constant evolution of teaching work and allows the construction of knowledge to transform educational practices, also helping to overcome the difficulties encountered in the classroom. This study aimed to analyze the teachers' perceptions about a formative process, from the STS approach, for teaching practice. The training process was carried out with teachers of elementary and high school, in a public school, in Santa Maria, Rio Grande do Sul (RS), mediated by pedagogical workshops, which included the STS approach in the school context. The data were obtained through a semistructured questionnaire, composed of two questions, and subsequently the content analysis methodology was used to analyze the data. The results demonstrated contributions in teaching practices, associated mainly with new teaching strategies, which collaborated for the development of educators, and favored an interdisciplinary and contextualized teaching. Continuing education also indicated benefits such as student motivation and interaction, thus favoring teaching and learning. Therefore, it is an indispensable part in the training of teachers, proposals such as the STS approach in the school context, since it cooperated to rethink training, and benefited actions centered on reflections on pedagogical practice.
\end{abstract}

Keywords: Science-Technology-Society. Teaching practice. Teacher continued Education. 


\section{Introdução}

A formação de professores tem sido foco de muitas discussões nas últimas décadas sendo considerada um processo permanente e componente essencial da profissionalização, desenvolvido em programas promovidos dentro e/ou fora das instituições de ensino, inspirado nos diferentes saberes e na experiência docente, integrando-a ao cotidiano das escolas (BRASIL, 2002; 2015).

A complexidade de fatores que permeiam a formação de professores é abrangente e associa-se ao desenvolvimento da escola, do ensino, do currículo e da profissão docente e evidencia aspectos relevantes que constituem a atuação pedagógica. Dessa forma, conhecer o professor, sua formação básica e como ele se constrói ao longo da sua carreira profissional são fundamentais para que se compreendam as práticas pedagógicas dentro das escolas (NÓVOA, 1995).

A formação de professores está prevista nos documentos oficias da educação brasileira. Segundo as Diretrizes Curriculares Nacionais (DCN) constitui-se como um processo direcionado à melhoria permanente da qualidade social da educação e à valorização profissional, à preparação e ao desenvolvimento de profissionais (BRASIL, 2015). A Lei de Diretrizes e Bases da Educação (LDB) prevê programas de educação continuada para os profissionais de educação em seus diversos níveis (BRASIL, 1996). A Resolução 02/2015 do Conselho Nacional de Educação (CNE), em seu artigo $n^{\circ} 16$, ressalta que a formação continuada compreende o repensar do processo pedagógico, sobre a prática educacional e a busca de aperfeiçoamento técnico, pedagógico, ético e político do profissional docente (BRASIL, 2015). Recentemente publicada, a Base Nacional Comum Curricular (BNCC) destaca que é necessário criar e disponibilizar materiais de orientação para os professores, e manter processos permanentes de formação docente que possibilitem contínuo aperfeiçoamento dos processos de ensino e aprendizagem (BRASIL, 2017; 2018).

A literatura discorre sobre as contribuições da formação continuada para a evolução constante do trabalho do docente, permitindo ao educador construir conhecimentos capazes de transformar em suas práticas educativas, além de auxiliar nas dificuldades encontradas no cotidiano da sala de aula. Neste sentido, torna-se necessário repensar a prática educacional, a fim de contemplar as inovações e o desenvolvimento associados a ciência e a tecnologia. Para Santos (2007), considerar a educação científica como cultura científica permite popularizar o conhecimento científico. Assim, no campo educacional, o movimento Ciência-Tecnologia-Sociedade (CTS) tem buscado uma abordagem crítica e contextualizada 
sobre questões relacionadas ao desenvolvimento científico e tecnológico (AULER; DELIZOICOV, 2006b; FERNANDES; STRIEDER, 2016).

Na educação básica, o objetivo da Educação CTS é favorecer a educação científica e tecnológica dos estudantes, auxiliando-os a construir conhecimentos, habilidades e valores essenciais para que possam tomar decisões responsáveis e construam um olhar crítico sobre o papel da ciência e da tecnologia na sociedade, uma vez que esse enfoque amplia os debates em sala de aula acerca de questões políticas, econômicas, culturais, sociais, ambientais e éticas (SANTOS; MORTIMER, 2000). Posto isso, educar numa perspectiva CTS é possibilitar uma formação para inserção social das pessoas, no sentido de se tornarem aptas a participar dos processos de tomadas de decisões conscientes em assuntos que envolvam ciência e tecnologia (LINSINGEN, 2007).

Dessa forma, os documentos que atuam diretamente na educação básica como as Diretrizes Curriculares Nacionais Gerais da Educação Básica ressaltam que uma formação integral traz o acesso ao conhecimento científico; a reflexão crítica sobre padrões culturais; as metodologias de ensino inovadoras, ativas e comprometidas com o aprender, voltadas a contextualização, problematização, vivências, realidade do educando, e de forma interdisciplinar (BRASIL, 2013). Os Parâmetros Curriculares Nacionais enfatizam os conteúdos socialmente relevantes e processos de discussão coletiva de temas e problemas reais (BRASIL, 1998). A BNCC manifesta que é importante salientar os múltiplos papéis desempenhados pela relação ciência-tecnologia-sociedade, no posicionamento e na tomada de decisões frente aos desafios éticos, culturais, políticos e socioambientais (BRASIL, 2017).

Assim, observa-se que as orientações educacionais estão em consonância com os propósitos da Educação CTS, voltadas para uma prática pedagógica que contribua na formação de sujeitos críticos, e que podem ser relacionadas a formação cidadã (SANTOS; SCHNETZLER, 2015). Para Linsingen (2002), a educação CTS deve alcançar os aspectos da didática, e o objetivo do professor deve ser a promoção de uma atitude crítica e criativa, na perspectiva de construir coletivamente a aula e nos espaços de aprendizagem, criando um ambiente propício para o que o autor chama de "construção coletiva".

Neste sentido, "é importante o papel do educador enquanto organizador e mediador de conteúdos, de modo a atender às necessidades, interesses, e curiosidade dos alunos, utilizando metodologias adequadas para tornar significativa a aprendizagem" (NASCIMENTO, 2020, p. 36). Assim, para promover a alfabetização científica e a formação cidadã, é preciso desenvolver estratégias que aprimorem as práticas na sala de aula (BAZZO; 
PEREIRA, 2008), de forma a trazer novas questões para a prática pedagógica, articulando novos saberes na construção da docência (IMBERNÓN, 2010).

Em consonância, Nascimento (2020) evidencia a necessidade de implantação de programas de formação continuada, por meio da perspectiva CTS, no intuito de possibilitar a reflexão pelos professores sobre sua própria prática docente, ensejando a ampliação dos conhecimentos teórico e metodológicos, para a efetivação de uma prática pedagógica efetiva. Ribeiro, Santos e Prudêncio (2020) complementam que, a formação do professor a partir da Educação CTS pretende construir novas significações da docência, mudar concepções preconcebidas sobre as relações entre Ciência-Tecnologia-Sociedade, bem como visões acerca do papel do professor nesse cenário.

Neste contexto, a importância da formação continuada para o aprimoramento dos professores tem sido apontada por muitos autores (AULER, 2002; DELIZOICOV; LOPES; ALVES, 2005; AULER; DELIZOICOV, 2006a; AUGUSTO; AMARAL, 2015; ROSO; AULER, 2016). Destarte, processos formativos que contemplem tais perspectivas, podem trazer melhorias para a prática pedagógica, uma vez que desenvolvem compreensões sobre o que, por que e como ensinar de acordo com a perspectiva CTS (FERNANDES; STRIEDER, 2016).

Considerando o exposto, para que os professores sejam capazes de implementar em suas atividades didáticas ações alinhadas aos objetivos da educação CTS, faz-se necessário repensar o processo de formação. Em conformidade, esse estudo se propôs a investigar as percepções dos professores sobre um processo formativo realizado no contexto escolar, a partir do enfoque Ciência-Tecnologia-Sociedade.

\section{Método}

\section{Contexto da investigação}

Essa pesquisa integra um trabalho colaborativo que iniciou em 2011, por meio de uma parceria estabelecida entre os pesquisadores de uma universidade pública federal e uma instituição escolar. Ao longo dos anos, diversos processos formativos, com diferentes enfoques e temáticas, dedicaram-se às demandas da comunidade escolar (LIMA, 2014; ROSSI, 2014; CARLAN, 2016; ILHA, 2016; WOLLMANN, 2016; VISINTAINER, 2018; LIMA, 2019; RODRIGUES, 2020, MENEZES, 2021).

Nesse contexto colaborativo estabeleceu-se uma sistemática cíclica de identificação das demandas e planejamento de estratégias pedagógicas, as quais orientaram novas formas de ações e reavaliações que desencadearam novos planejamentos continuamente. Nessa 
perspectiva, é importante ressaltar que durante o ano letivo de 2019, o ambiente escolar esteve fisicamente organizado em salas temáticas. Nesse arranjo, em fase de experimentação, a gestão escolar solicitou aos docentes que todas as salas apresentassem um projeto trimestral, que foi orientado por "Temas Integradores", definidos coletivamente pelo corpo docente (MENEZES et al., 2020a). Essa proposta buscou contextualizar o ensino, contemplando temáticas articuladas com a realidade dos estudantes e associadas à formação cidadã. Assim, evidenciou-se a necessidade de um processo formativo que contemplasse as demandas emergentes.

\section{Procedimentos Metodológicos}

Esse estudo contempla os aspectos de uma pesquisa qualitativa, com abordagem de caráter exploratório e descritivo, conforme Gil (2008). Foi realizado no ano de 2019, em uma escola da rede pública de Santa Maria/RS, vinculada à $8^{a}$ Coordenadoria Regional de Educação, que oferta os níveis de Ensino Fundamental e Médio. No referido ano estiveram matriculados 166 estudantes nos Anos Iniciais, 218 nos Anos Finais, 126 no Ensino Médio e 25 na Educação Especial ${ }^{1}$. O quadro organizacional da escola contava com cinco professoras atuando na gestão e 35 em regência de classe.

Em consequência da sistemática de trabalho colaborativo incorporada nesse contexto escolar, todo o corpo docente foi convidado a participar do processo formativo, efetivado em quatro encontros presenciais na sede da escola, os quais foram realizados trimestralmente, para que dessa forma os professores pudessem contemplar em seus planejamentos aspectos da educação CTS, que foram abordados no curso. Todavia alguns professores conciliavam atividades em outras instituições de ensino e não puderam participar de todos os encontros. Assim, 23 docentes perpassaram as formações. Destes, 20 responderam a um questionário semiestruturado, composto por duas questões, o qual foi aplicado no último encontro com intuito de identificar as percepções dos professores sobre o processo formativo.

A concepção e planejamento desse processo formativo estiveram orientados pela Alfabetização Científica e consideraram: a educação CTS, sua inserção na educação básica e nos documentos oficiais da educação; a abordagem de temas sociocientíficos e estratégias de ensino; as relações CTS e uma educação voltada para a formação da cidadania; a educação

\footnotetext{
${ }^{1}$ Informações disponíveis no site https://www.qedu.org.br; na qual é uma plataforma que contém os principais dados do ensino básico.
} 
ambiental através da abordagem CTS; as inter-relações CTS em diversos contextos, envolvendo os Objetivos do Desenvolvimento Sustentável (ODS) da Agenda 2030 da ONU (ONU, 2015).

Considerando que técnicas de investigação realizadas por meio de questionários podem ser utilizadas para obter informações sobre conhecimentos, interesses, expectativas (GIL, 2008), um questionário semiestruturado foi aplicado para identificar as percepções dos professores sobre o processo formativo. Nas questões se indagava: "De que modo a formação continuada com a proposta Ciência-Tecnologia-Sociedade ajudou ou está lhe ajudando na sua prática docente"? e "Na sua opinião, quais dificuldades, obstáculos, ganhos ou facilidades a adoção de metodologias diferentes das tradicionais - como as propostas de Ciência-Tecnologia-Sociedade trazem para o ensino-aprendizagem"?

As respostas foram digitadas e o conteúdo foi analisado seguindo o método proposto por Bardin (2016), compreendendo as etapas de pré-análise, exploração do material, definição das categorias, inferências e interpretações. As respostas foram categorizadas de acordo com as aproximações observadas. Em complemento, para contribuir com informações sobre esse processo foram apresentados fragmentos das respostas dos docentes, utilizando de referência a letra P como indicador do professor e suas falas, e os numerais 1, $2,3,[\ldots]$, fazendo distinções das falas entre um e outro.

Esse estudo contemplou todos os preceitos éticos, quanto à participação dos docentes, e foi aprovado pelo Comitê de Ética em Pesquisa, conforme CAAE aprovado pela universidade. Portanto todos os envolvidos assinaram o Termo de Consentimento Livre e Esclarecido (TCLE), com garantia de anonimato.

\section{Resultados e Discussões}

Na perspectiva CTS, a formação de professores requer situações formativas pautadas na reflexão crítica individual e coletiva sobre a docência (LIMA et al., 2019). Nessa premissa, esse estudo se propôs a investigar as percepções dos professores de uma escola pública sobre um processo formativo, desenvolvido a partir da educação CTS.

Quando os docentes foram questionados sobre: "De que modo a formação continuada com a proposta Ciência-Tecnologia-Sociedade ajudou ou está lhe ajudando na sua prática docente? ", manifestaram uma variedade de respostas, as quais convergiram para quatro categorias. Os fragmentos a seguir, são respostas obtidas e as categorias que emergiram das falas estão apresentados no Quadro 1 abaixo: 
Quadro 1 - Contribuições da formação continuada como a proposta CiênciaTecnologia-Sociedade

\begin{tabular}{|c|c|}
\hline Planejamento & $\begin{array}{l}\text { P5 “trazendo apoio para desenvolver os projetos” } \\
\text { P6 “contribuiu na construção dos projetos" } \\
\text { P7 “apoio, disponibilidade na realização dos projetos” }\end{array}$ \\
\hline Prática pedagógica & $\begin{array}{l}\text { P17 “proporcionou espaços durante o ano letivo para discussões, e sobre a } \\
\text { prática pedagógica" } \\
\text { P12 “com um novo olhar sobre o processo de ensino-aprendizagem e suas } \\
\text { implicações na prática pedagógica cotidiana” } \\
\text { P9 “me ajudou a refletir e me orientar a prática pedagógica usada” } \\
\text { P } 15 \text { “enriquecer relações e desacomodar” }\end{array}$ \\
\hline $\begin{array}{l}\text { Aprofundamento } \\
\text { teórico }\end{array}$ & P15 "para ampliar os conhecimentos" \\
\hline Novas estratégias & $\begin{array}{l}\text { P20 "trouxe subsidios que possibilitam pensar novas estratégias } \\
\text { metodológicas" } \\
\text { P16 “no conhecimento de novas estratégias de ensino" } \\
\text { P11 "possibilitou estabelecer novas estratégias no ensino- aprendizagem" } \\
\text { P8 “mantém o grupo focado em planejar ações com diferentes estratégias, e } \\
\text { em busca de metodologias" } \\
\text { P4 “novas possibilidades, aprender coisas diferentes", }\end{array}$ \\
\hline
\end{tabular}

Fonte: Elaboração das autoras, 2020.

Conforme as percepções dos docentes em suas respostas, as categorias resultantes apontam que o processo formativo contribuiu em diversos aspectos para a prática docente dos participantes. Dentre os aspectos referidos nas falas, ressalta-se a questão do planejamento, aprofundamento teórico, e novas estratégias, que possibilitaram o professor a construir e desenvolver suas atividades, que envolveram os docentes na forma de aprimorar suas práticas pedagógicas por meio de novas estratégias e trouxeram benefícios ao ensino e a aprendizagem.

Segundo a categoria "Planejamento", a formação contribuiu no desenvolvimento e na construção dos projetos elaborados pelos docentes. Os projetos realizados pelas educadoras estiveram voltados para situações significativas no contexto escolar, desse modo propiciaram a contextualização dos conteúdos com as demandas identificadas e apresentadas pela escola. Ribeiro, Santos e Prudêncio (2020) salientam que o planejamento conjunto proporciona o olhar para as demandas da escola, e que o planejamento cooperativo de práticas CTS para a sala de aula, permitem a construção de propostas de ensino mais próximas da realidade escolar. Logo, os excertos das respostas evidenciam que a concepção 
e construção dos projetos conduziram o planejamento pedagógico das docentes, e possibilitaram estabelecer os objetivos que foram desenvolvidos ao longo do ano. Essas observações estão em conformidade com a proposição de Araújo (2014, p. 155, grifo do autor) que considera que a utilização de projetos permite a “[...] reorganização das ações educativas, dimensões complementares de conteúdos, de forma e de relações entre professor e estudante".

Lima et al. (2019) ressalta que a formação inicial ou continuada de professores na perspectiva CTS, requer situações formativas pautadas principalmente na reflexão crítica individual e coletiva sobre a docência, na pesquisa e prática interdisciplinar, na contextualização dos conhecimentos e no enfrentamento dos desafios para práticas curriculares transformadoras. Desse modo, o planejamento estabelecido para o ano letivo dos docentes, favoreceu a prática pedagógica, uma vez que os projetos proporcionaram suporte metodológico na construção das atividades e permitiram aos professores refletirem sobre sua prática. Como pode ser observado na fala da P10: “ajudou no sentido de fazer refletir sobre a prática, dar ideias de como trabalhar". Corroborando com Nóvoa (1995), o qual cita que a formação se constrói através de um trabalho de reflexividade crítica sobre as práticas e de (re)construção permanente de uma identidade pessoal.

Dessa forma, questionar a própria prática é um dos desafios da profissão docente, porém também cabe como recurso para melhorar a prática pedagógica. Conforme a fala da P15, na qual as formações enriquecem as práticas e desacomodam, assim o professor abarca o desenvolvimento de novas propostas, como uma forma de melhorar o seu desempenho e gerar novos saberes, assim como cita Paulo Freire: “[...] intervir na realidade, tarefa incomparavelmente mais complexa e geradora de novos saberes do que simplesmente a de nos adaptar a ela" (FREIRE, 1996, p. 40).

As práticas pedagógicas, quando desenvolvidas de forma interdisciplinar almejam a melhoria no processo. Esse aspecto foi evidenciado na fala da P2, a qual comenta que o processo formativo contribuiu "na visão interdisciplinar". Neste sentido, o caráter interdisciplinar da educação CTS permite o envolvimento de diversas disciplinas nas discussões (STRIEDER, 2012). Assim, entende-se que a interdisciplinaridade está além de uma simples integração de conteúdos, trata-se de construir um processo comunicativo entre disciplinas, de tal forma que seja possível compreender os fenômenos estudados (RODRÍGUEZ; DEL PINO, 2017). Convém lembrar, conforme referido anteriormente, que este contexto escolar tem experenciado, ao longo dos anos, um ambiente colaborativo de trabalho por meio da utilização de projetos interdisciplinares de ensino-aprendizagem, como 
destacado por Carlan (2016), Visintainer e Soares (2019), Rodrigues (2020), Menezes et al. (2020b).

Giacomini e Muenchen (2015) trazem relatos de uma experiência de formação continuada de professores em uma escola estadual da região central do Estado do Rio Grande do Sul. As autoras ressaltam a importância do trabalho coletivo e interdisciplinar que caracterizou as atividades desenvolvidas com os professores, bem como do ambiente descontraído e dialógico mobilizado pela reflexão e ação demonstrada pelos mesmos.

A prática educativa é um espaço entre docente, conhecimento, currículo e metodologia de ensino. Assim, Freire (1996) configura pelo fazer docente, na busca pelo ser mais, da formação permanente, do inacabamento do humano e do assumir-se pesquisador do seu fazer pedagógico e da sua ação docente. Nessa perspectiva, a categoria "Aprofundamento teórico" emergiu segundo a fala dos docentes, na qual demonstram que a formação permitiu o aprofundamento teórico do docente, como citado pela P15, que ressaltou a "ampliação dos conhecimentos".

Outra categoria que emergiu foi "Novas estratégias". Bazzo e Pereira (2008) relatam que é possível promover um ensino CTS, utilizando estratégias de ensino e metodologias diferenciadas. Nessa perspectiva, novas estratégias levam o docente a mudanças nas suas ações educativas, o que pode ser observado nas falas dos docentes: "a formação trouxe algumas ideias de trabalho que favoreceram na hora de colocar em prática o trabalho (P19) " e "ajudou em novas estratégias de ensino e possibilidade" (P13). Corroborando com Rodríguez e Del Pino (2017), os quais salientam que a perspectiva CTS, pode ser entendido como fundamento da prática pedagógica sendo possível explorar uma ampla quantidade de estratégias metodológicas de acordo com as necessidades do contexto escolar.

Cabe salientar que as categorias que emergiram das falas dos docentes, se complementam, pois, a formação permitiu um planejamento pedagógico para atividades pedagógicas, e dessa forma a prática pedagógica, por meio de novas estratégias, amplia os conhecimentos, e traz benefícios e subsídios a prática do professor com o seu discente.

Um segundo questionamento considerou quais dificuldades, obstáculos, ganhos ou facilidades a adoção de metodologias diferentes das tradicionais - como as propostas de Ciência-Tecnologia-Sociedade - trazem para o ensino-aprendizagem? Assim, alguns fragmentos das falas dos docentes estão apresentados nos Quadros 2 e 3. O Quadro 2 mostra a percepção dos docentes sobre os benefícios da proposta CTS, e o Quadro 3 exibe a percepção dos docentes sobre as dificuldades e obstáculos da proposta CTS no processo de ensino-aprendizagem. 
Quadro 2 - Percepção dos docentes sobre os benefícios da proposta CTS no processo de ensino-aprendizagem.

\begin{tabular}{|c|c|}
\hline $\begin{array}{lr}\text { Motivação } & \text { e } \\
\text { interesse } & \text { dos } \\
\text { estudantes } & \end{array}$ & $\begin{array}{l}\text { P10 "Considero que ajudou na alegria de aprender dos alunos" } \\
\text { P5 "Interesse do aluno" }\end{array}$ \\
\hline $\begin{array}{l}\text { Melhora no } \\
\text { processo ensino- } \\
\text { aprendizagem }\end{array}$ & $\begin{array}{l}\text { P4 “Novas aprendizagens, novas ideias, novas oportunidades. Tudo contribuindo } \\
\text { para um novo e próspero caminho" } \\
\text { P6 “Elaborar projetos para as aulas são positivos na aprendizagem” } \\
\text { P8 “Com certeza são ganhos para o ensino aprendizagem” } \\
\text { P11 “torna mais atrativo o ensino-aprendizagem” } \\
\text { P13 “E os ganhos são as experiências e novas oportunidades de ensinar e aprender. } \\
\text { As coisas se tornam mais fáceis quando bem planejadas" } \\
\text { P12 "Surge como um desafio, uma quebra de paradigma, e uma construção de } \\
\text { sentido para o ensino" }\end{array}$ \\
\hline $\begin{array}{l}\text { Possibilita } \\
\text { protagonismo } \\
\text { estudantil }\end{array}$ & $\begin{array}{l}\text { P14 "Penso que as diferentes metodologias contribuem para desenvolver o } \\
\text { protagonismo discente" } \\
\text { P11 "Há maior interação dos educandos" } \\
\text { P18 "contribuem para o melhor envolvimento dos alunos em um processo de } \\
\text { aprendizagem" }\end{array}$ \\
\hline
\end{tabular}

Fonte: Elaboração das autoras, 2020.

Ao questionar os docentes, foi possível verificar aspectos favoráveis ao processo de ensino-aprendizagem. Uma categoria que emergiu das falas foi relativa a "Motivação e interesse dos estudantes". Os professores relataram que a proposta CTS, trouxe benefícios aos estudantes, e conduziram a motivação e interesse por parte dos mesmos. E dessa forma pode-se complementá-la a categoria com outra já citada anteriormente: "Novas estratégias". Muitos autores como Teixeira (2003), Santos e Schnetzler (2015), Roso e Auler (2016), e Acevedo et al. (2017) citam as estratégias de ensino como benéficas e relevantes para as práticas pedagógicas, por motivar o interesse do estudante fazendo com que as aulas sejam diferenciadas, e assim, oportunizando mais a aprendizagem. Santos e Mortimer (2000) ressaltam que a educação CTS se apresenta como forma de motivação e uma prática diferenciada, com foco no ensino de conhecimentos científicos e na compreensão das interrelações CTS.

Em um estudo realizado por Bettencourt, Almeida e Velho (2014), o qual visou diagnosticar as dificuldades, as vantagens e as percepções de professores sobre a concepção e implementação de estratégias CTS, os resultados apontaram a motivação dos estudantes pelos conteúdos relacionados com a ciência, a tecnologia e a sociedade. Os autores 
constataram que diferentes estratégias de ensino e de aprendizagem conduziram a diferentes níveis de motivação por parte dos estudantes. Nesse sentido, o uso de algumas estratégias para o desenvolvimento das atividades em sala de aula potencializa essas inter-relações, ou seja, indo ao encontro do que fora exposto neste estudo.

Apesar das distintas respostas, os professores, quando questionados sobre os benefícios da proposta CTS, também apontaram para o educando como foco das atividades. Dessa forma, emergiu a categoria "Possibilita o protagonismo estudantil". As características do enfoque CTS incentivam novas formas de envolver os estudantes e propicia espaços de interação, o qual produz aprendizagens para todos os envolvidos no processo (RODRÍGUEZ; DEL PINO, 2019). Santos e Schnetzler (2015) afirmam que a educação CTS desenvolve a participação e a tomada de decisão dos cidadãos, além da formação cidadã.

Assim, observa-se que a proposta ao ser implementada trouxe motivação e proximidade para estudantes, e a realização de processos na qual envolveram os discentes, os tornaram mais participativos. Corroborando com Rodríguez e Del Pino (2019) os quais ressaltam que na proposta CTS o papel do estudante muda, ele deixa de ser um agente passivo receptor, para ser produtor de seu próprio conhecimento, pois o foco desta abordagem está no educando.

De acordo com os professores foi possível identificar que o envolvimento com a proposta CTS trouxe benefícios à prática docente, apontando para uma melhoria no ensinoaprendizagem, conforme foi evidenciado nos fragmentos das respostas que originaram a categoria "Melhora no processo ensino-aprendizagem".

Auler e Delizoicov (2006a) sinalizam os benefícios da introdução da educação CTS para a alfabetização científica dos educandos, pois promovem o interesse pela Ciência, ajudam a melhorar o espírito crítico, o pensamento lógico e a tomada de decisão. Santos e Schnetzler (2015) relatam que a implementação CTS pode melhorar qualitativamente o processo ensino-aprendizagem. De tal modo, a afirmação do autor, pode ser confirmada por meio dos excertos das docentes, exibidos no Quadro 2.

Ao relacionar CTS em sala de aula, o professor irá favorecer o conhecimento científico de seu discente. E isso retorna em melhorias na prática em sala de aula, trazendo novas aprendizagens, ideias, tornando o ensino mais atrativo e dinâmico, como relatado pelos docentes. Dessa forma, será ofertado um ensino mais reflexivo e contextualizado, em sintonia com a perspectiva CTS, refletindo na melhoria da aprendizagem.

Santos e Mortimer (2001) citam questões que dificultam e criam entraves para o desenvolvimento do ensino CTS. A partir das respostas dos docentes, algumas dificuldades 
e obstáculos para a implementação de uma abordagem CTS foram identificadas, e emergiram três categorias: "Carência de recursos didáticos adequados; Tempo para planejamento e Resistência às mudanças", que podem ser observadas no Quadro 3 abaixo.

Quadro 3 - Percepção dos docentes sobre as dificuldades e obstáculos da proposta CTS no processo de ensino-aprendizagem

\begin{tabular}{|c|c|}
\hline $\begin{array}{l}\text { Carência de } \\
\text { recursos } \\
\text { didáticos } \\
\text { adequados }\end{array}$ & $\begin{array}{l}\text { P19 "Uma dificuldade são os recursos como computadores com internet para todos } \\
\text { os alunos”, } \\
\text { P6 “Os obstáculos são a internet que não funciona, e o acesso ao computador" } \\
\text { P5 “As ideias são bem-vindas, porém alguns recursos impedem os resultados, como } \\
\text { a limitação da internet”" }\end{array}$ \\
\hline $\begin{array}{l}\text { Tempo para } \\
\text { planejamento }\end{array}$ & P2 "Tempo para planejamento individual ou em parceria com outras áreas" \\
\hline $\begin{array}{l}\text { Resistência às } \\
\text { mudanças }\end{array}$ & $\begin{array}{l}\mathrm{P} 13 \text { "Um obstáculo de por parte de alguns alunos e professores" } \\
\mathrm{P} 6 \text { "Tudo que é "novo e diferente" vem como um obstáculo até o momento da } \\
\text { realização" }\end{array}$ \\
\hline
\end{tabular}

Fonte: Elaboração das autoras, 2020.

A categoria "Tempo para planejamento", emergiu pelo que fora mencionado pela docente P2. O planejamento individual ou coletivo com outros colegas de trabalho é impossibilitado ou prejudicado em função da restrição de tempo. Deste modo, a dificuldade na administração do tempo influencia na implementação de estratégias de ensino e aprendizagens inovadoras, e também na participação de formações ofertadas. Essas observações estão em consonância com o estudo de Bettencourt, Almeida e Velho (2014), que identificaram como dificuldades, o tempo necessário para planejar e preparar as tarefas de aprendizagem dos professores, na implementação da educação CTS.

A categoria "Carência de recursos didáticos adequados" manifestou-se dos relatos dos docentes, que apontaram a falta de recursos como dificuldades ou obstáculos para realizar a proposta CTS no processo ensino-aprendizagem. Segundo Perrenoud (2000) a importância da utilização de novas tecnologias encontra-se entre as dez competências para ensinar no século XXI, pois, de acordo com o autor, deve-se utilizar as novas tecnologias, explorar as ferramentas multimídias no ensino e explorar as suas potencialidades didáticas. Os recursos evidenciados pelos docentes relacionam-se à falta de recursos tecnológicos. E esse aspecto passa a ser perceptível aos docentes, e então relatado como falta dele, na qual para o docente, limita a realização de suas práticas educativas, que poderiam abarcar a tecnologia, e relacioná-la no ensino, de forma que o professor tenha acesso a ferramentas científicas e tecnológicas, e possa dispor uma postura de abordagem crítica, fazendo um intercâmbio de informações. 
Pinheiro, Silveira e Bazzo (2007) citam que é necessário levar para sala de aula o debate sobre as relações existentes entre CTS e a compreensão da origem e o uso que se faz desses recursos tecnológicos na sociedade. Porém, compreende-se que o uso das TICs pode se constituir em uma estratégia a mais para enriquecer o planejamento e a ação didática na educação CTS, mas não deve ser um recurso essencial. A partir dos excertos dos docentes, considera-se que os mesmos apresentam ainda uma concepção bastante reduzida e limitada de ciência e tecnologia, e de que a falta das TICs (internet e computador) implica num grande obstáculo.

Ressalta-se que as TICs podem estar presentes nas práticas pedagógicas e serem utilizadas como estratégia didática de ensino, mas é necessário realizar um trabalho pedagógico desenvolvido a partir de conteúdos relevantes no contexto e realidade do estudante, estimulando reflexões referentes aos interesses, valores políticos, sociais, econômicos, ambientais, éticos, científicos e culturais, entre outros. Assim, a prática que o docente realiza busca formar indivíduos capazes de interagir nos debates sobre o desenvolvimento científico-tecnológico e influenciar nas decisões que afetam a sociedade, ter e manifestar opinião a seu respeito (PINHEIRO; SILVEIRA; BAZZO, 2007).

Outra categoria que surgiu foi "Resistência às mudanças". Os resultados desse estudo demonstram que, apesar dos benefícios consequentes do processo formativo nas práticas docentes, a resistência às mudanças ainda está presente no contexto escolar. Essa oposição pode estar associada ainda pela falta de recursos, como já relatado anteriormente, ou das dificuldades relativas às condições de trabalho que os professores enfrentam. Comiotto et al., (2019) identificou as concepções quanto a CTS, ensino/aprendizagem e prática pedagógica de 26 acadêmicos que atuam em sala de aula. Os resultados citados foram: a falta de recursos, a resistência de professores ao uso de novas tecnologias, a desvalorização profissional, a infraestrutura escolar, entre outros como provas e exames. Esses obstáculos também foram referidos por Imbernón (2010) que ressalta a existência de contradições em algumas dificuldades atestadas pelos docentes que podem converter-se em resistência às mudanças.

Segundo Acevedo (1996) as dificuldades para os professores incorporarem CTS em suas aulas correspondem à resistência comum a todas as inovações educacionais, devido à natureza, geralmente conservadora dos sistemas de ensino, e também ao desconhecimento da maioria dos professores relativas às estratégias de ensino e aprendizagem. Santos (2007) alerta que professores apresentam resistência e dificuldades em promover reflexões e debates que contemplem questões sociais. Para o autor, essa dificuldade faz com que muitas vezes, 
a educação CTS esteja restrita a meras ilustrações de aplicações tecnológicas, sem a relação devida com as implicações sociais. Assim, é preciso inserir a abordagem CTS de maneira a favorecer a criticidade do sujeito em sala de aula.

Sobretudo, um ponto importante a se considerar é que uma perspectiva CTS de ensino requer modificação no perfil tradicional da ação docente (ACEVEDO, 1996). Destarte, a proposta de incorporar ao ensino uma discussão sobre as inter-relações CTS dependerá da disponibilidade para a mudança e a renovação por parte dos professores. Nesse sentido, o interesse e a determinação em superar os desafios que emergem nos processos de inovação no ensino, têm estreita relação com a disponibilidade e com o compromisso subjacente aos professores (FIRME; AMARAL, 2011).

Segundo Imbernon (2010) a formação docente deve centrar-se na instituição educacional e estar comprometida com a identificação e o esforço de modificar as práticas desenvolvidas no interior da instituição e para além delas, definindo processos individuais e coletivos. Ribeiro, Santos e Prudêncio (2020) mapearam os trabalhos que articulam Educação CTS à formação de professores. Os resultados apontam que as ações formativas aconteceram principalmente nas disciplinas da formação inicial, e não fomentaram relações entre a academia e a escola. Dessa forma, ressalta-se que o estudo desenvolvido em virtude do trabalho colaborativo, entre os pesquisadores e a instituição escolar, permitiu contemplar um processo formativo que considerasse as demandas emergentes da escola, e aproximou as discussões CTS na prática educativa. Outra característica identificada pelos autores referenciados acima, foram que as pesquisas analisadas, estavam inseridas em processos formativos, porém a maioria dos estudos direcionados à CTS na formação, não incluíram como referencial, os pesquisadores que abordam a formação de professores. Por conseguinte, como forma de contemplar um processo formativo que visasse a reflexão acerca da prática, numa perspectiva dialógica de articulação entre teoria e prática, esse estudo levou em consideração os fundamentos teóricos que têm sustentado as discussões sobre a formação de professores, e também a formação no âmbito da Educação CTS.

Portanto, evidencia-se a necessidade de favorecer na formação continuada de professores, discussões relacionadas à Educação CTS para a prática educativa efetiva no contexto escolar, centradas em reflexões sobre a prática pedagógica, associadas à elaboração e desenvolvimento de propostas de ensino, articuladas ao contexto em que se insere.

\section{Considerações Finais}

Com base nas percepções dos professores, os resultados desse estudo indicam que o processo formativo possibilitou melhorias e mudanças nas práticas docentes, permitindo que 
o professor desenvolvesse os projetos e planejamentos, por meio de discussões e estabelecer uma nova perspectiva sobre o processo de ensino-aprendizagem e suas implicações na prática pedagógica, através de novas estratégias.

Como resultante desse processo, considerando a proposta e as análise realizadas, compreende-se que a formação continuada indicou benefícios nas práticas pedagógicas dos docentes, como a motivação e interação dos estudantes, assim favorecendo o ensinoaprendizagem. Ainda nesse contexto, salienta-se a importância dos cursos de formação continuada, pois oportunizam ao professor novas possibilidades didático-pedagógicas e ainda, colaboram com discussões importantes sobre as diversas circunstâncias de ensinoaprendizagem e dificuldades vivenciadas na Educação Básica, conforme apresentadas pelos docentes, na qual destacaram as suas dificuldades e obstáculos ao propor a educação CTS. Ademais, a possibilidade de realização desses processos dentro da instituição de ensino escolar permitiu uma grande adesão dos docentes e a garantia de espaço e tempo para a formação continuada.

Visto que o processo formativo abarcou a proposta CTS, pode-se assegurar que a formação contribuiu na reflexão da prática docente, e consequentemente nas atividades pedagógicas, a partir da interação entre ciência, tecnologia e sociedade, na qual propicia o desenvolvimento de conteúdos ligados à realidade dos educandos, promovendo a contextualização e permitindo uma formação crítica dos mesmos.

Sendo assim, faz-se como parte indispensável na formação de professores, propostas como a educação CTS no contexto escolar, visto que cooperou para o repensar sobre a formação, e beneficiou ações centradas em reflexões sobre a prática pedagógica, associadas a novas estratégias de ensino, que colaboraram na elaboração e desenvolvimento dos educadores, pois a compreensão sobre as inter-relações Ciência-Tecnologia-Sociedade dos professores pode favorecer um ensino interdisciplinar e contextualizado.

\section{Financiamento e agradecimentos}

Os autores agradecem o apoio da Coordenação de Aperfeiçoamento de Pessoal de Nível Superior (CAPES).

\section{Referências}

ACEVEDO, J. A. La formación del profesorado de enseñanza secundaria y la educación CTS. Una cuestión problemática. Revista Interuniversitaria de Formación del Profesorado, v. 26, n. 26, p. 131-144, 1996. 
ARAUJO, U. Temas transversais, pedagogia de projetos e as mudanças na educação. 1 . ed. São Paulo: Summus, 2014.

AUGUSTO, T. G. da S.; AMARAL, I. A. do. A formação de professoras para o ensino de ciências nas séries iniciais: análise dos efeitos de uma proposta inovadora. Ciência \& Educação, Bauru, v. 21, n. 2, p. 493-509, 2015.

AULER, D. Interações entre Ciência - Tecnologia - Sociedade no Contexto da Formação de Professores de Ciências. 2002. Tese (Doutorado em Educação Científica e Tecnológica) - Universidade Federal de Santa Catarina, Florianópolis, 2002. Disponível em: https://repositorio.ufsc.br/handle/123456789/82610. Acesso em: 15 ago. 2020.

AULER, D.; DELIZOICOV, D. Ciência-Tecnologia-Sociedade: relações estabelecidas por professores de ciências. Revista Electrónica de Enseñanza de las Ciencias, v. 5, n. 2, 2006a.

AULER, D.; DELIZOICOV, D. Educação CTS: articulação entre pressupostos do educador Paulo Freire e referenciais ligados ao Movimento CTS. In: SEMINÁRIO IBÉRICO CTS NO ENSINO DAS CIÊNCIAS, 2006b, Malagá. Anais [...]. Malagá: Universidad de Málaga, 2006b, p.1-7.

BARDIN, L. Análise de conteúdo. 1. ed. São Paulo: Edições 70, 2016.

BAZZO, W. A.; PEREIRA, L. T. do V. O que é CTS afinal na educação tecnológica. Revista Tecnologia \& Cultura, v. 13, p. 46-54, 2008.

BETTENCOURT, C.; ALMEIDA, A. P.; VELHO, J. L. Implementação de estratégias Ciência-Tecnologia-Sociedade (CTS): percepções de professores de biologia. Investigações em Ensino de Ciências, v. 19, n. 2, p. 243-261, 2014. https://www.if.ufrgs.br/cref/ojs/index.php/ienci/article/view/79/54\%3E. Acesso em: 10 out. 2020.

BRASIL. Lei n. 9.394, de 20 de dezembro de 1996. Dispõe sobre as Diretrizes e Bases da Educação Nacional. Disponível em: http://www.planalto.gov.br/ccivil 03/leis/19394.htm. Acesso em: 29 jul. 2020.

BRASIL. Parâmetros curriculares nacionais: Ciências Naturais. Brasília: MEC/SEF, 1998.

BRASIL. Referenciais para formação de professores. Brasília: Ministério da Educação, 2002.

BRASIL. Diretrizes Curriculares Nacionais Gerais da Educação Básica. Brasília: MEC/SEB, 2013. Disponível em: http://portal.mec.gov.br/docman/julho-2013pdf/13677-diretrizes-educacao-basica-2013-pdf/file. Acesso em: 29 jul. 2020.

BRASIL. Resolução $\mathbf{n}^{\mathbf{0}}$ 2, de $\mathbf{1}^{\mathbf{0}}$ de julho de 2015. Define as Diretrizes Curriculares Nacionais para a formação inicial em nível superior (cursos de licenciatura, cursos de formação pedagógica para graduados e cursos de segunda licenciatura) e para a formação continuada. Disponível em: http://portal.mec.gov.br/docman/agosto-2017pdf/70431-res-cne-cp-002-03072015-pdf/file. Acesso em: 29 jul. 2020.

BRASIL. Base Nacional Comum Curricular. Brasília: MEC, 2017. Disponível em: http://basenacionalcomum.mec.gov.br/. Acesso em: 29 jul. 2020.

BRASIL. Base Nacional Comum Curricular. Brasília: MEC, 2018. Disponível em: http://basenacionalcomum.mec.gov.br/. Acesso em: 13 out. 2020. 
CARLAN, C. B. Influência de projetos pedagógicos interdisciplinares na atividade física habitual e no estado nutricional de escolares do ensino fundamental. 2020. Dissertação (Mestrado em Educação em Ciências: Químicas da Vida e Saúde) - Universidade Federal do Rio Grande do Sul, Porto Alegre, 2016.

COMIOTTO, T. et al. Concepções sobre práticas pedagógicas e ensino/aprendizagem sob a perspectiva de Ciência, Tecnologia e Sociedade (CTS). Revista de Estudos Aplicados em Educação, v. 4, n. 7, jan./jun., 2019.

DELIZOICOV, N. C.; LOPES, A.; ALVES, E. B. D. Ciências Naturais nas Séries Iniciais: características e demandas no ensino de Ciências. In: ENCONTRO NACIONAL DE PESQUISA EM EDUCAÇÃO EM CIÊNCIAS, 5., Bauru, 2005. Anais [...]. Bauru: UNESP, 2005.2 Disponível em: http://www.nutes.ufrj.br/abrapec/venpec/conteudo/artigos/3/pdf/p348.pdf. Acesso em: 29 ago. 2020.

FERNANDES, R. F.; STRIEDER, R. B. Questionamentos e Opiniões de professores de Ciências da Natureza sobre Educação CTS. Indagatio Didactica, v. 8, n.1, p. 453467, 2016.

FIRME, R. do N.; AMARAL, E. M. R. do. Analisando a implementação de uma abordagem CTS na sala de aula de Química. Ciência \& Educação, v. 17, n. 2, p. 383-399, 2011.

FREIRE, P. Pedagogia da autonomia: saberes necessários à prática educativa. São Paulo: Paz e Terra, 1996.

GIACOMINI, A.; MUENCHEN, C. Os três momentos pedagógicos como organizadores de um processo formativo: algumas reflexões. Revista Brasileira de Pesquisa em Educação em Ciências, v. 15, n. 2, p. 339-355, 2015.

GIL, A. C. Como elaborar projetos de pesquisa. 4. ed. São Paulo: Atlas, 2008.

ILHA, P. V. Contribuições da pesquisa colaborativa na prática pedagógica docente, utilizando a aprendizagem de projetos como estratégia de ensino. 2016. Tese (Doutorado em Educação em Ciências) - Universidade Federal de Santa Maria, Santa Maria, 2016.

IMBERNÓN, F. Formação continuada de professores. Porto Alegre: Artmed, 2010.

LIMA, A. P. dos S. Ensino multidisciplinar na melhoria do conhecimento nutricional no ensino fundamental. 2014. Dissertação (Mestrado em Educação em Ciências) Universidade Federal de Santa Maria, Santa Maria, 2014.

LIMA, N. W. et al. Reiki no SUS e o Misticismo Quântico: Reflexões a partir do posicionamento de alunos de Licenciatura em uma aula de Física Quântica sob a perspectiva CTS. In: ENCONTRO NACIONAL DE PESQUISA EM EDUCAÇÃO EM CIÊNCIAS, 12., 2019, Natal. Anais [...]. Natal: ABRAPEC, 2019.

LIMA, A. P. dos S. Formação continuada de professores de uma escola pública estadual, visando a inserção das TIC em sala de aula. 2019. Tese (Doutorado em Educação em Ciências) - Universidade Federal de Santa Maria, Santa Maria, 2019.

LINSINGEN, I. V. Engenharia, tecnologia e sociedade: novas perspectivas para uma formação. 2002. Tese (Doutorado em Educação) - Universidade Federal de Santa Catarina, Centro de Ciências da Educação, Florianópolis, 2002.

LINSINGEN, I. V. Perspectiva educacional CTS: aspectos de um campo em consolidação na América Latina. Ciência \& Ensino, v. 1, número especial, 2007. 
MENEZES, M. K. et al. Ressignificando o espaço escolar através de salas temáticas: uma experiência educativa em construção em uma escola pública. In: RIGUE, F. M.; AMESTOY, M. B. O que pode a educação no Brasil hoje? 1. ed. Veranópolis: Diálogo Freiriano, 2020a.

MENEZES, K. M.; RODRIGUES, C. B. C.; CANDITO, V.; SOARES, F. A. A. A pesquisa como articuladora das práticas pedagógicas: contribuições de um processo formativo. Inter-Ação, 45, n. 3, p. 856-873, 2020 b.

MENEZES, M. K. Contribuições da pedagogia de projetos para a educação em saúde no contexto escolar. 2021. Tese (Doutorado em Educação em Ciências) Universidade Federal de Santa Maria, Santa Maria, 2021

NASCIMENTO, V. F. do. Ciencias, tecnologias e sociedade na prática do professor de ciências: entre a formação e a sala de aula. Curitiba: Appris, 2020.

NÓVOA, A. Formação de professores e profissão docente. In: NÓVOA, Antônio (Org.). Os professores e a sua formação. 2. ed. Portugal: Publicações Dom Quixote, 1995.

ONU. Organização das Nações Unidas. Transformando Nosso Mundo: A Agenda 2030 para o Desenvolvimento Sustentável. 2015. Disponível em: https://brasil.un.org/sites/default/files/2020-09/agenda2030-pt-br.pdf. Acesso em: $14 / 03 / 2021$.

PERRENOUD, P. Dez novas competências para ensinar. Porto Alegre: Artmed Editora, 2000.

PINHEIRO, N. A. M.; SILVEIRA, R. M. C. F.; BAZZO, W. A. A relevância do enfoque CTS para o contexto do ensino médio. Ciência \& Educação, v. 13, n. 1, p. 71-84, 2007.

RIBEIRO, K. S.; SANTOS, D. F.; PRUDÊNCIO, C. A.V. Ciência, tecnologia e sociedade: formação de professores e aproximação universidade-escola. \#Tear: Revista de Educação, Ciência e Tecnologia, Canoas, v. 9, n.1, 2020.

RODRÍGUEZ, A. S. M.; DEL PINO, J. C. Abordagem Ciência, Tecnologia e Sociedade (CTS): perspectivas teóricas sobre educação científica e desenvolvimento na América Latina. TEAR: Revista de Educação Ciência e Tecnologia, v. 6, n. 2, p. $1-21,2017$.

RODRÍGUEZ, A. S. M.; DEL PINO, J. C. O Enfoque Ciência, Tecnologia e Sociedade (CTS) na Reconstrução da Identidade Profissional Docente. Investigações em Ensino de Ciências, v. 24, n. 2, p. 90-119, 2019.

RODRIGUES, C. B. C. Intervenções no ambiente escolar visando a promoção da saúde. 2020. Tese (Doutorado em Educação em Ciências) - Universidade Federal de Santa Maria, Santa Maria, 2020.

ROSO, C. C.; AULER, D. A participação na construção do currículo: práticas educativas vinculadas ao movimento CTS. Ciência \& Educação, Bauru, v. 22, n. 2, p. 371$389,2016$.

ROSSI, D. S. Imagem corporal, aspectos nutricionais e atividade física em estudantes. 2014. Dissertação (Mestrado em Educação em Ciências) - Universidade Federal de Santa Maria, Santa Maria, 2014. 
SANTOS, W. L. P. dos; MORTIMER, E. F. Uma análise de pressupostos teóricos da abordagem C-T-S (Ciência - Tecnologia - Sociedade) no contexto da educação brasileira. Ens. Pesqui. Educ. Ciênc., Belo Horizonte, v. 2, n. 2, p. 110-132, 2000.

SANTOS, W. L. P. dos; MORTIMER, E. F. Tomada de decisão para ação social responsável no ensino de ciências. Ciência \& Educação, Bauru, v. 7, n. 1, p. 95-111, 2001.

SANTOS, W. L. P. dos. Contextualização no ensino de ciências por meio de temas CTS em uma perspectiva crítica. Ciência \& Ensino, v. 1, número especial, p. 1-12, 2007.

SANTOS, W. L. P. dos; SCHNETZLER, R. P. Educação em Química: Compromisso com a cidadania. Ijuí: UNIJUÍ, 2015.

STRIEDER, R. B. Abordagens CTS na educação científica no Brasil: sentidos e perspectivas. 2012. Tese (Doutorado em Ensino de Física) - Faculdade de Educação, Instituto de Física, Instituto de Química e Instituto de Biociências, Universidade de São Paulo, 2012. Disponível em: https://www.teses.usp.br/teses/disponiveis/81/81131/tde-13062012112417/publico/Roseline_Beatriz_Strieder.pdf. Acesso em: 02 ago. 2020.

TEIXEIRA, P. M. A educação científica sob a perspectiva da pedagogia histórico-crítica e do movimento C.T.S. no ensino de ciências. Revista Ciência e Educação, v. 9, n. 2, p.177-190, 2003.

VISINTAINER, D S. R. Oficinas Pedagógicas como estratégia para a promoção da saúde na formação docente continuada. 2018. Dissertação (Mestrado em Educação em Ciências) - Universidade Federal de Santa Maria, Santa Maria, 2018.

VISINTAINER, D S. R.; SOARES, F. A. A. O desenvolvimento de estratégias de ensino para a promoção da saúde na formação docente continuada. Contexto \& Educação, v. 34, n. 109, p. 52-73, 2019.

WOLLMANN, E. M. A inserção da educação ambiental na formação de professores: das percepções, às práticas. 2016. Tese (Doutorado em Educação em Ciências) Universidade Federal de Santa Maria, Santa Maria, 2016.

Vanessa Candito

Graduada em Ciências Biológicas. Mestranda no PPG em Educação em Ciências: Química da Vida e Saúde pela Universidade Federal do Rio Grande do Sul. Possuo Especialização Lato Sensu em Ciências Ambientais pela URI - de Frederico Westphalen, e Especialização Lato Sensu em Educação Ambiental, pela UFSM/RS. Áreas de Conhecimento e Interesse de Pesquisa: Ensino de Ciências e Biologia, Educação Ambiental e Sustentabilidade, Elaboração de Projetos e Formação de Professores, (CTS)Ciência-Tecnologia-Sociedade Participante do Grupo de Estudos Transdisciplinares (GET), da Universidade Federal de Santa Maria. Participante do Grupo de Estudo em Nutrição, Saúde e Qualidade de Vida (GENSQ), da Universidade Federal de Santa Maria vanecandito@gmail.com http://orcid.org/0000-0003-4663-9590 
Karla Mendonça Menezes

Licenciada e Bacharel em Educação Física pela Universidade Federal de Santa Maria (2007), Especialista em Atividade Física, Desempenho Motor e Saúde pela Universidade Federal de Santa Maria (2009), Mestra em Distúrbios da Comunicação Humana pela Universidade Federal de Santa Maria (2011) e Mestra em Educação Física pela Universidade Federal de Santa Maria (2016). Atualmente é aluna de Doutorado no PPG Educação em Ciências: Química da Vida e Saúde - UFSM e instrutora de esporte e lazer no Serviço Social do Transporte (SEST SENAT). Membro da Associação Brasileira de Pesquisa em Educação em Ciências. Integrante do Grupo de Estudos em Nutrição, Saúde e Qualidade de Vida - GENSQ (UFSM) e do Grupo de Estudos e Pesquisa em Promoção e Educação em Saúde- GEPPES (UNIPAMPA). Tem experiência na área de Educação em saúde, exercício físico para populações especiais, doenças crônicas não transmissíveis, determinantes em saúde, crescimento e desenvolvimento motor, controle postural e Equoterapia. karlam.ef@gmail.com http://orcid.org/0000-0002-7482-0648

Carolina Braz Carlan Rodrigues Licenciada em Educação Física pela Universidade Luterana do Brasil, especialista em Treinamento, Musculação e Atividade Física na Faculdade Ingá (UNINGÁ - SM), mestre em Educação em Ciências: Química da Vida e Saúde na Universidade Federal do Rio Grande do Sul e Doutora em Educação em Ciências: Química da Vida e Saúde na Universidade Federal de Santa Maria. carolinabcarlan@gmail.com http://orcid.org/0000-0001-7115-0987

Maria Rosa Chitolina Schetinger possui graduação em Biologia pela Universidade Federal do Rio Grande do Sul (1988), mestrado em Ciências Biológicas (Bioquímica) pela Universidade Federal do Rio Grande do Sul (1991), doutorado em Ciências (Bioquímica) pela Universidade Federal do Paraná (1996) e pós-doutorado no Albert Einstein College of Medicine/USA (2015). É professora titular da Universidade Federal de Santa Maria e possui bolsa em produtividade em pesquisa nível 1B do CNPq. Atualmente é vice-presidente do Clube Brasileiro de Purinas. Tem experiência na área de Bioquímica, com ênfase em Enzimologia, atuando principalmente nos seguintes temas: NTPDase, 5'-nucleotidase, acetilcolinesterase, ALA-

$\mathrm{D}$, catalase e superóxido dismutase em diferentes doenças em humanos e em modelos experimentais. Também, está trabalhando em Educação em Ciências, em ensino, aprendizagem e cienciometria. mariachitolina@gmail.com https://orcid.org/0000-0002-5240-8935 